\title{
ABRIR-SE PARA A FAMÍLIA: SUPERANDO DESAFIOS
}

\author{
GETTING CLOSE TO FAMILIES: OVERCOMING CHALLENGES
}

Margareth Angelo ${ }^{1}$

RESUMO: A família como perspectiva está influenciando a prática e a teoria na enfermagem. A despeito do desenvolvimento acadêmico existente, no entanto, a pesquisa e as narrativas de estudantes e de enfermeiros evidenciam as dificuldades presentes na experiência de estar com as famílias nas situações de enfermagem. Neste artigo, a autora analisa três desafios que necessitam ser superados para facilitar a aproximação e o trabalho com famílias em enfermagem: ensinar a pensar família, estimular uma prática avançada com famílias e ajudar a construir o conhecimento em enfermagem da família. A autora conclui abordando a dimensão humanística presente na superação dos desafios, como uma condição para aumentar as possibilidades de cuidado para os enfermeiros e as famílias.

PALAVRAS CHAVE: Família; Enfermagem.

\section{INTRODUÇÃO}

A família como parte essencial para o cuidado de enfermagem é algo inquestionável. As evidências que os estudos nos trazem, os depoimentos que os estudantes e enfermeiros nos têm fornecido acerca de suas dificuldades para aproximarem-se da família e o que vemos nas experiências das próprias famílias, em meio ao seu sofrimento, tudo contribui para a sustentação de que a família está aí entre cada um de nós, vivendo inevitavelmente momentos difíceis que demandam dela ações, sentimentos e pensamentos, às vezes, heróicos, porque ultrapassam em muito suas possibilidades conhecidas, e necessitando de um enfermeiro capaz, que Ihes ajude a olhar estes momentos como possibilidades de crescer e de superar-se naquelas habilidades e virtudes humanas que lhes faltam.

São muitas as dificuldades existentes no caminho daqueles enfermeiros que se dispõem a abrir-se para a família. Muitas vezes, esta é uma jornada solitária que compreende experiências e visões de mundo nem sempre partilhadas por outras pessoas. 0 humanismo presente em nossos atos com a família, é por vezes difícil de ser compreendido e acessado por muitos dos que conos co convivem em nosso cotidiano profissional.

Uma silenciosa revolução está ocorrendo no cenário da enfermagem, influenciada por iniciativas solitárias a princípio, de cuidar da família, norteadas pela fidelidade à verdade principal de que nenhuma família consegue existir sem algum tipo de apoio, pelos conceitos sobre família que têm sido desenvolvidos, e agora por uma emergente política pública destinada à saúde da família.

A ênfase crescente na família tem resultado na modificação da maneira como ela é percebida no contexto de saúde, ultrapassando-se sobretudo as definições utilitárias que se atribuía à família, quando era vista exclusivamente como um bem para o paciente, e sua presença era considerada e, às vezes, tolerada, em especial nos ambientes de assistência à saúde, levando-se em conta seu papel na esfera afetiva da recuperação do familiar doente.

Durante anos, a enfermagem vem direcionando sua prática com famílias para ações basicamente de orientação e de busca de informações. A família fica, neste sentido, restrita a ser receptáculo e fonte de informações. As ações de apoio oferecidas são tímidas e pouco efetivas, porque não atingem a experiência da família e sequer a do enfermeiro,que se deixa guiar pelo perigoso bom-senso que se fundamenta no sentimentalismo ou na busca de satisfação pessoal, e que entre tantas realizações é responsável pelo estabelecimento de códigos que se tornam regras, nos quais se definem como devem se sentir e agir famílias em determinadas circunstâncias.

1 Enfermeira. Professor Associado do Departamento de Enfermagem Materno-Infantil e Psiquiátrica da Escola de Enfermagem da Universidade de São Paulo e Coordenadora do Grupo de Estudos em Enfermagem da Família (GEENF). 
É preciso mais do que emoção e regras para trabalhar com família. Estas considerações, falam-nos da necessidade de utilizar guias internos mais efetivos. É preciso que se desenvolvam e se apliquem modelos conceituais mais amplos para uma prática avançada com famílias. Felizmente esta visão tem sido cada vez mais partilhada por enfermeiros, que inicialmente munidos de fortes sentimentos em relação à família, empreendem uma jornada pessoal em busca de conhecimento, através de teoria e de exemplos práticos.

A orientação cada vez mais crescente para um trabalho em que a família esteja efetivamente contemplada, está criando um novo clima nos ambientes de atendimento à saúde, para a maneira de olhar a família. A pessoa e sua doença não são mais os principais focos de atenção do enfermeiro. A família é, também, vista como foco desta atenção.

Esta mudança na ênfase para a família como um domínio emergente na enfermagem, evidenciado sobretudo pela avanço teórico que a área vem tendo, aliada ao fato de que este mesmo movimento na prática ainda é muito tímido, quase inexistente, torna a área ainda essencialmente acadêmica, o que traz algumas implicações para os que estudam a área de enfermagem da família, que consiste em verdadeiro desafio, que pode ser subdividido em três esferas: ensino, prática e pesquisa.

Não devemos pensar que esta seja uma situação exclusiva de nosso meio, do nosso país. Este é um desafio para todos os enfermeiros, porque a enfermagem da família ainda não é uma realidade em muitos contextos do mundo.

Duhamel (1995) apresenta algumas questões que certamente estão presentes em cada um dos enfermeiros que identifica estes vazios e este lento desenvolvimento da abordagem da família em muitos contextos: Os enfermeiros reconhecem a importância da família na saúde e na doença? Os enfermeiros sabem como adquirir uma melhor compreensão das experiências da família e como lidar com elas? Como os enfermeiros pensam para cuidar da família? Os enfermeiros oferecem cuidado adequado e efetivo? Como a efetividade é medida?

R efletindo cuidadosamente sobre cada uma destas questões, apresento algumas considerações acerca de como percebo os desafios para a enfermagem da família e algumas estratégias que tenho utilizado em relação a eles. Para ilustrar, utilizarei depoimentos que venho obtendo ao longo dos encontros que tenho experienciado com alunos e enfermeiros, nesta trajetória de trabalho na área de enfermagem da família.

\section{DESAFIO 1: ENSINAR A PENSAR NA FAMÍLIA}

0 ensino de enfermagem tem grande responsabilidade pela maneira como os estudantes e, conseqüentemente, os enfermeiros pensam a família. J á tive oportunidade de dar meu próprio testemunho de como uma professora, ainda na graduação, levou-me concretamente a voltar-me em direção à família, e esta sua ação teve como conseqüência a minha sensibilização para a família. Eu passei a pensar em família, e esta foi a base sobre a qual edifiquei o meu trabalho com família.

A crescente evolução do conhecimento existente na área de enfermagem da família ainda não tem resultado em sua aplicação na mesma intensidade, na prática. A observação mostra que nem todos os contextos concebem família como parte de sua prática, e que mesmo entre aqueles em que tradicionalmente a família está presente, como na pediatria ou na obstetrícia, nem todos os enfermeiros consideram família como foco de sua atenção.

A sensibilização fornecida por uma formação que considere a família como contexto ou como centro do cuidado, desde a graduação, é o elemento essencial que preenche um vazio que uma estrutura curricular que toma como eixo exclusivamente $o$ indivíduo, pode provocar.

Estar sensibilizado é ser capaz de reconhecer a família como um fenômeno complexo que demanda apoio em tempos de dificuldades, sobretudo na situação de doença, é considerar a importância da família para o cuidado de enfermagem e também a importância do cuidado da família em suas experiências de saúde e doença, tendo como meta promover um funcionamento pleno da família.

Poucos enfermeiros espontaneamente pensam sobre o funcionamento da família, sobre as experiências da família na situação de doença e mesmo sobre o cuidado da família, apesar de estarem expostos rotineiramente às situações com famílias que enfrentam dificuldades, tanto em hospitais como em assistência domiciliar, e outros contextos de assistência. Isto ocorre simplesmente porque não foram formados com a habilidade de "pensar família", utilizando um termo bastante apropriado, proposto por Green (1997). Segundo esta autora, um componente básico da formação para prover cuidado de enfermagem que atenda às experiências da família na doença, é a habilidade de "pensar família". 
Assim, pensar família é estar sensibilizado para ela, e isto envolve basicamente a compreensão e apreciação da complexidade interacional da vida familiar.

Percebo que a sensibilização é um elemento crucial no estabelecimento de uma relação destinada ao cuidado da família, já que interfere na decisão pessoal do enfermeiro em cuidar da família e, assim, buscar recursos e criar formas de ser e de agir com a família.

Depoimentos de enfermeiros a respeito de como se sentem para lidar ou trabalhar com famílias, permitiram compreender a diferença resultante quando o olhar para a família é norteado pela sensibilidade e quando é ocultado pelo vazio do desconhecimento

"Sinceramente eu não sei o que fazer com a família do recém-nascido, porque tudo o que eu falar não sei se vai adiantar. Não sei o que fazer; a gente não aprende isso, faltou..."

"Eu sinto que a família precisa de mim, eu vou até eles, mesmo sem saber como fazer e com um pouco de receio do que eles podem estar querendo."

Estar sensibilizado não significa saber trabalhar com a família. Não é o conhecimento, mas predispõe a ele, seja ao conhecimento da própria família ou ao conhecimento específico de enfermagem da família. Quanto ao vazio do desconhecimento, este gera medo e imobilidade, e cria regras das quais o profissional passa a depender, para que as interações aconteçam.

A situação do ensino sobre família nos cursos de graduação em enfermagem tem sido objeto de estudo na área de enfermagem de família. 0 primeiro estudo que tem servido de modelo para outros, foi realizado por WRIGHT; BELL (1989) que investigaram a situação do ensino sobre família em enfermagem no Canadá, seguido por HANSON; HEIMS (1992), que o replicaram, estudando a situação das escolas nos Estados Unidos. Ambos os estudos encontraram que um conteúdo mais geral sobre família estava presente nos cursos do que havia no passado e uma abordagem eclética era ensinada. A prática clínica nos cursos de graduação, no entanto, ainda tinha como foco o indivíduo. Na ocasião em que os estudos foram publicados, as autoras recomendaram a necessidade de uma maior integração de conteúdos sobre família nos cursos, a aprendizagem de modelos e de estratégias de avaliação de família e de experiências clínicas voltadas para famílias. Mais recentemente, algumas escolas já mais sensibilizadas para a temática família na formação do enfermeiro, apresentam estratégias, algumas inovadoras para ensinar estudantes sobre família, que são apresentadas nos trabalhos de Green (1997), Tapp; Moules; Bell; Wright (1997) e Friedman (1997).

Buscando evidências acerca do ensino sobre família no Brasil, estamos desenvolvendo um estudo no qual já dispomos de alguns dados quantitativos sobre a situação do ensino de enfermagem da família nas escolas de enfermagem no Brasil (Angelo; P ettengill, 1997). Apenas para fins de ilustração e não propriamente de análise, temos que de 14 escolas do Estado de $S$ ão Paulo, que forneceram as informações, 8 não ministram aulas formais sobre família, sendo que a carga horária destinada ao tema varia entre 6 e 15 horas; apenas 1 possui carga horária ao redor de 40 horas. Quanto ao conteúdo, este compreende a definição de família e de saúde da família, técnicas de entrevista e processo de trabalho com família. Das 6 escolas que ministram conteúdo sobre família, duas o fazem através de disciplina formal sobre família. Nas demais, o conteúdo está integrado em outras disciplinas. Nestas escolas, 10 referiram não haver docente com preparo específico sobre família. Como se trata de um estudo em andamento, ao mesmo tempo em que os dados do restante do país estão sendo analisados, estamos procedendo também entrevistas com docentes das escolas, para compreender a vivência em relação à temática família na formação do enfermeiro e conhecer mais profundamente a situação do ensino sobre família na enfermagem; pelos dados iniciais ainda não se encontra bem incorporada aos programas dos cursos, a exemplo do Canadá ou Estados Unidos.

Para que a enfermagem da família torne-se uma realidade, o ensino sobre família deve iniciar na graduação, como parte essencial da formação do enfermeiro e não como algo opcional. U ma prática avançada com famílias em enfermagem, só é possível se o enfermeiro incorporar ou estiver sensibilizado desde a graduação, à família como unidade de cuidado, compreendendo, avaliando e considerando como foco de atenção o relacionamento entre as interações familiares e as experiências de saúde e doença.

Nossa experiência no ensino sobre família na graduação, foi decorrente do contato com alunos em nível de pós-graduação, alguns deles docentes de enfermagem, que sequer estavam sensibilizados para a família.

0 ensino, na minha prática docente está estruturado desde 1995, através de uma disciplina específica (Enfermagem e Família), além de incluir vivências planejadas no contexto de saúde da criança, contém ainda o recurso de um grupo de estudos (Grupo de Estudos em Enfermagem da Família), que além de constituir um 
fórum de discussões e pesquisas sobre o tema família e enfermagem, é também uma oportunidade para os estudantes participarem do processo de construção de conhecimento na área.

"Para mim ficou muito claro todo o processo de atuação da enfermeira, o processo da família. Eu estou com um problema em casa, uma pessoa doente, estamos vivendo uma verdadeira reviravolta em termos de sentimentos, crenças, papéis. Na verdade, se a minha família pudesse ter contato com uma enfermeira com quem pudesse conversar e receber orientações sobre essa doença, como lidar com o doente, seria ótimo..."

"R efletindo sobre as aulas dadas, acabei compreendendo que assistir uma família não é apenas detectar problemas físicos e encaminhar a especialistas. É também ouvi-la e tentar fazê-la visualizar seu problema e lhe dar opções de resolução de acordo com sua ideologia, com o que ela achar que pode sanar o seu problema."

Ainda que recente a experiência, posso afirmar que estes recursos, embora quase optativos no contexto de formação, para os alunos que o utilizam, estão fazendo uma grande diferença na sua sensibilidade e no seu olhar para a família. Além destas, que aqui estão apresentadas com fins de ilustração de uma experiência pessoal, outras estratégias podem e devem ser criadas segundo os recursos das instituições, e utilizadas para acolher o desafio de ensinar a pensar família.

\section{DESAFIO 2: ESTIMULAR UMA PRÁTICA AVANÇADA COM FAMÍLIA}

O que distingue uma prática avançada de uma prática generalista, é a maneira como pensamos, a linguagem que utilizamos, as questões que formulamos e os relacionamentos que valorizamos.

Muitos enfermeiros reconhecem o significado da enfermagem da família, mas somente uma minoria assegura sua prática. Falta de tempo, de conhecimentos e de habilidades, tem sido citados como os principais fatores que impedem uma aproximação mais consistente da família. A prioridade é habitualmente dada ao cuidado físico e a outras questões de ordem administrativa. Sem desconsiderar a importância destes aspectos, o fato é que os enfermeiros costumam perceber o trabalho com a família como "fazendo algo a mais", como refere Neman (1996) em seu estudo. Em termos de sensibilidade para o tema, esta percepção do trabalho com família evidencía que alguns enfermeiros não conseguem pensar família e considerar o potencial inerente de uma abordagem centrada na família, para poupar tempo e esforço e evidentemente ser mais efetivo no resultado da intervenção.

Considerando o contexto de formação dos enfermeiros, que pouco tem contribuído para a sensibilização e a existência de poucos supervisores ou coordenadores de equipe que possuam uma visão voltada para a família, o que resulta em pouco apoio administrativo para este aspecto do cuidar, a implementação de uma prática voltada também para a família, chega a ser quase impossível.

Os enfermeiros que estão sensibilizados para a família, e me atrevo a dizer que não são poucos, são unânimes em referir os obstáculos institucionais para a atenção à família, e os malabarismos que precisam fazer, para não ferirem normas estabelecidas e ao mesmo tempo acolherem a família.

"Quem cuida de família, está sempre correndo riscos. As pessoas ficam de olho na gente, como se estivéssemos fazendo algo errado. Eu procuro ter muito cuidado, para não agredir a instituição, mas também não deixo de cuidar da família"

“Tenho colegas que acham que eu protejo as famílias, que quero ser boazinha com elas, que dou muita abertura. Dizem que as normas estão aí para serem atendidas e as famílias têm que aceitar. Não concordo e continuo, porque acredito que faço bem meu trabalho tanto para o serviço como com a família, mesmo sabendo que estou desafiando uma forma coletiva de ver a família."

Estes depoimentos nos dão uma idéia de alguns aspectos da experiência do enfermeiro que pensa família num contexto que não tem a mesma sensibilidade. Quando falo de sensibilidade, é preciso que fique claro que não se trata de sentimentalismo, de deixar-se levar por sentimentos em relação à família. A sensibilidade a que me refiro trata-se de uma disposição interna para agir, que denominamos vontade, estimulada pela inteligência que confere ao enfermeiro a capacidade de desenvolver conhecimento, não exclusivamente acadêmico, mas proveniente da reflexão sobre a realidade que o cerca, no cotidiano vivido com as famílias. Afinal, não são estes os ingredientes básicos do desenvolvimento da ciência e da técnica? Ter sensibilidade, portanto, é ter conhecimento também.

“Vejo que a família quer notícias sobre o paciente que está na recuperação anestésica, e eu não sei como lidar com isso" 
"Ao longo dos anos, tenho identificado a importância da participação da família na recuperação do paciente e o sofrimento que ela passa. Queria muito saber como ajudá-las."

O que vemos hoje na prática, é que temos duas possibilidades de estar com a família: enfermeiros não sensibilizados e enfermeiros sensibilizados mas pouco instrumentalizados.

A instrumentalização é outro aspecto que juntamente com a sensibilização ajuda no estímulo a uma prática avançada, e consiste em dispor de recursos de conhecimento que capacitem o enfermeiro a pensar e agir com a família. A a proximação dos enfermeiros ao conhecimento existente sobre família, como referenciais teóricos, instrumentos de avaliação, estratégias de aproximação e relacionamento com a família, técnicas de intervenção, capacita-os a pensar família, a utilizar uma linguagem apropriada e a formular questões acerca da prática que realiza. Pode-se dizer que a instrumentalização, torna as coisas mais confortáveis para o enfermeiro, pois ao mesmo tempo em que o capacita para agir numa direção determinada, fortalece a sua disposição para continuar a buscar sempre novas formas de ser e de agir com a família.

A instrumentalização além de capacitar o enfermeiro, pode atuar como um elemento de sensibilização para outros enfermeiros. Se fizermos um exercício e pensarmos interacionalmente, sob a ótica do interacionismo simbólico, veremos que o enfermeiro ao interagir com mais segurança, possibilitada pelos recursos de conhecimento que dispõe, pode ter suas ações consideradas, simbolicamente falando, de modo diferente pelas outras pessoas do ambiente, o que poderá levar estas pessoas a reverem suas próprias ações, e assim, poderão também modificar sua perspectiva e conseqüentemente suas ações. Um dos aspectos do interacionismo simbólico, é que a intervenção, qualquer que seja ela, sempre se dá na dimensão das definições. Assim, se queremos ações diferentes dos profissionais, temos que possibilitar um contexto, onde novas definições possam emergir. É possível transformar expressões como: "eu não tenho jeito", "eu não tenho paciência, não tolero, não suporto", "preciso me poupar para não me desgastar", em depoimentos indicativos de que o enfermeiro está menos preocupado com a idéia de se economizar como ser humano.

"Antes eu achava que tinha que ser boazinha com a família. A minha visão de família se alterou desde que estou nestes estudos sobre família. Vejo agora o paciente juntamente com a família e não individualmente."

"Adquiri mais compreensão, pois pensamos apenas no paciente e esquecemos que a família faz parte também do nosso trabalho. É um recurso tanto para o paciente como para nós. Precisamos aprender como utilizar melhor."

"Os relatos de experiências das colegas enriqueceram e clarearam muitas dúvidas. Vejo que tenho mais esta responsabilidade em minha vivência profissional como professora do interior do Estado."

"Sinto que agora tenho mais segurança e coragem para de repente lutar pela saúde do paciente e de seus familiares, e fazer com que fiquem juntos e unidos nos momentos difíceis."

"Posso ajudar minhas colegas a verem o lado da família, mostrando os estudos, os instrumentos. Acho que podem ajudar muito, para que elas não se sintam mais tão perdidas diante da família."

Os depoimentos que utilizamos neste texto, são provenientes de encontros do Grupo de Estudos em Enfermagem da Família, de seminários, de cursos e de disciplinas sobre família que temos realizado. Com isso, posso dizer seguramente que o desafio para a prática avançada com família, consiste em criar estratégias e mecanismos institucionais, e aqui incluo tanto a escola como o serviço, destinados a promover a sensibilização e a instrumentalização do enfermeiro para estar com a família.

\section{DESAFIO 3: AJ UDAR A CONSTRUIR O CONHECIMENTO DE ENFERMAGEM DA FAMÍLIA}

Uma das questões formuladas no contexto da enfermagem da família é: até que ponto a ausência de uma prática de enfermagem da família não está sendo atribuída ao conhecimento disponível?

Possuímos já conhecimentos consistentes acerca da importância do trabalho com a família, das repercussões da situação de doença para a família, de como a família afeta a saúde do indivíduo, de como crises de saúde são eventos críticos para a vida familiar. Parecem, no entanto, não serem ainda suficientes para transformar a prática.

Duhamel (1995) apresenta algumas questões que são significativas também para a nossa reflexão. Será que os enfermeiros consideram os resultados das pesquisas irrelevantes para sua prática? Será que as 
pesquisas realmente ajudam a compreender a dinâmica das interações familiares na saúde e na doença? Os estudos apresentam intervenções para a prática com família?

Analisando os estudos que tem sido realizados, vemos que a sua grande maioria consiste naqueles relativos a família, cujo foco é um membro da família. Estudos da família, somente nesta década estão sendo realizados, sobretudo porque faltavam instrumentos conceituais e metodológicos para o seu desenvolvimento.

À parte, estas restrições metodológicas, que nem são tão intransponíveis, o que mais dificulta 0 desenvolvimento do conhecimento, é não existência de dúvidas. É este aspecto que percebo como um desafio para a área de enfermagem da família: desejar compreender a verdade existente nas situações do cotidiano. Sem fascínio, sem mistério, seja porque se considera dominada a verdade, seja porque não exista o despertar para a existência de uma verdade, não há porque procurar qualquer coisa.

É preciso portanto, encontrar um porquê para empreender uma busca.

O caminho inicial consiste na disposição para olhar a realidade e os desconfortos que ela provoca. Sempre existe alguma coisa pelo menos, a estimular nossa indagação. Muitas vezes chegamos à compreensão de que nossa inquietação é a propósito da ausência de indagações em nós.

"Nunca pensei no meu relacionamento com a família. Sempre segui as regras das rotinas. Era tudo normal. A minha inquietação é que acho que não tenho perguntas, ou melhor, acho que não sei por onde começar!"

“Nunca me preocupei com família, pois não fui formada para isso. Mas agora que descobri família, como professora começo a me preocupar com os alunos. Como será que eles aprendem a cuidar no contexto de família, se na minha escola ninguém ensina sobre família?"

A busca das respostas, configura-se num caminho em que inevitavelmente nos deparamos com novas questões, sobretudo aquelas relativas às nossas possibilidades no processo de investigação e às nossas formas de interagir.

"Não consigo ouvir as respostas da família para as minhas perguntas, sem querer responder antes dela terminar a pergunta. Como faço para me controlar?"

"Eu nunca imaginei que minha colega pensasse em família. Com a entrevista percebi que ela não sabia agir como eu agia, e assim preferia se afastar da família."

O caminho da construção de conhecimento de enfermagem da família, é excitante, não apenas pelos conhecimentos que ele permite desvendar, mas principalmente, pelas verdades que cada um descobre dentro de si em relação a si mesmo no mundo.

"Descobri que antes, eu agia por pena da família. Agora, eu ajo porque eu a conheço, sei o que precisa e a respeito em sua forma de conduzir as coisas. Antes eu queria resolver o problema. Hoje eu quero participar da solução."

"Para compreender a família, é preciso acima de tudo muita humildade. Fico pensando como eu era capaz de olhar a família com ares de quem sabia tudo. Hoje eu quero aprender dela."

A construção do conhecimento de enfermagem da família, compreende antes de mais nada, motivar a formulação de perguntas sobre família e a busca de respostas tanto pessoais como teóricas. 0 conhecimento produzido provém de dúvidas, de incertezas e da vontade de pessoas inteiras, de superar os próprios limites para encontrar a verdade. Esta busca não é isenta de sofrimento, mas bem apoiada, é capaz de gerar conhecimento sólido e útil e também pessoas sólidas e indispensáveis ao contexto da família.

\section{DESAFIOS E CRESCIMENTO}

Acolher as possibilidades do outro, seus medos, seus sentimentos, seus vazios, seus preconceitos, seu ânimo, suas paixões. Não há uma condição ideal ou certa para iniciar o trabalho com família. Sempre haverá o que sensibilizar e o que instrumentalizar.

As condições pessoais do enfermeiro são um desafio para quem se dispõe a conduzi-lo no caminho de aprender e construir conhecimento. Ele precisa de um ambiente acolhedor, em que suas forças e fragilidades sejam consideradas como os elementos básicos, o ponto de partida para a construção de uma história com a família, da história dele. Ele precisa ser cuidado para interiorizar a experiência e transformá-la em ações de cuidado em relação ao outro, pessoa ou família. Cuidar se aprende cuidando, mas também sendo cuidado, 
basta ver a menina de dois anos cuidando de sua boneca. Ela sabe exatamente o que fazer, pelo conhecimento que desenvolveu no cuidado que recebe.

Se queremos enfermeiros sensibilizados, instrumentalizados e indagadores e empreendedores na construção de conhecimentos, isto será possível através da criação de um ambiente facilitador destas competências. Um ambiente que desenvolva a possibilidade humana de cada um deles.

Enfrentar desafios deve ser visto como estímulo para realizar grandes coisas, sem esperar feitos estrondosos inicialmente, mas a custa de pequenas coisas, de pequenas ações, seja um texto sobre o qual se comenta, um convite para assistir um curso ou um chamado para realizar um estudo. Tudo começa pequeno, mas o empenho de muitos pode tornar grande o pequeno, e nas ações destinadas a cuidar de uma única família, pode residir a essência da promoção da família como um todo e também a própria sociedade

Lembro-me de uma estória bastante contada, pelo tanto que contém de significado. Trata-se daquela sobre os três pedreiros que assentavam pedras, e que quando indagados sobre o que faziam, deram cada um uma resposta diferente. 0 primeiro disse que estava assentando pedras, o segundo que estava ganhando 0 sustento de sua família e o terceiro, que estava construíndo uma catedral.

Sejamos nós como este último personagem, que em cada pequena ação consigamos apreender que ela representa também a construção do todo de uma sociedade. Uma pedra que falte, por menor que possa parecer pode resultar em famílias mais vulneráveis e conseqüentemente numa sociedade menos resistente, e portanto menos saudável.

Em uma conferência, Martino (1995) falou sobre a necessidade social de considerar a família como um valor. Em suas palavras, "Viver juntos e viver melhor contribui para a construção de um ambiente mais completamente humano, no qual a primeira e fundamental estrutura para a ecologia humana é a família, na qual o homem recebe suas primeiras idéias formativas sobre verdade e bondade, e aprende o que significa amar $e$ ser amado, e assim o que exatamente significa ser uma pessoa."

Penso que todos os esforços daqueles que de algum modo trabalham com e pela família, o fazem movidos por esta idéia a respeito de família. Associar à concepção de saúde o conceito de ecologia, me parece algo muito apropriado à nossa visão de família como um ambiente de interações. As possibilidades de zelar por ele ou de destruí-lo dependem das ações e dos investimentos que nele são realizados.

Muitas vezes o ambiente familiar necessita de cura. Mas é de importância vital saber diferenciar ações que curam uma família, daquelas que a danificam.

"Curar significa ser capaz de ver o potencial para a conexão, plantar sementes de fortalecimento quando se toma uma história de desespero e a transforma em uma de esperança, quando se toma um história de traição e a transforma em uma de cuidado. Curar significa transformar experiências negativas em positivas, fracasso em oportunidade. Curar significa acreditar em famílias, em sua bondade e em seus reais esforços para fazer 0 melhor que podem. Significa acreditar na sabedoria da família, dando-Ihe permissão para encontrar seu próprio caminho, no seu próprio tempo, tendo como foco suas forças". Davies (1995)

A despeito de esforços no sentido de diminuir a importância da família, o fato é que não existe nada melhor para o ser humano do que a família. Nas palavras de Chesterton (1995), "A família é uma instituição boa, precisamente porque não é conciliadora. É algo bom e saudável precisamente porque contém tantas divergências e variedades, e como dizem as pessoas sentimentais, um pequeno reino, e como muitos outros reinos pequenos, encontra-se geralmente em um estado que se parece mais uma anarquia".

A grande aventura de estar com a família, reside exatamente de tomar parte numa história absolutamente imprevisível, a qual a família tem que enfrentar com as grandes limitações e possibilidades de que dispõe, os fatos que não gostaria de passar ou que não esperava ter que viver.

0 trabalho com família representa a possibilidade de ampliar nosso próprio mundo e nossa própria humanidade.

Ao evitarmos olhar para a família que faz parte de nosso cotidiano profissional, estamos escapando da vida que nos está sendo oferecida para participar. Quando saímos numa expedição de reconhecimento de uma situação e também de nós mesmos, sobretudo quando são áridas as condições, é um alívio encontrar algo que satisfaça ou atenda nossa condição humana, como uma água fresca para beber, um local para tomar banho, alguém para nos ouvir contar sobre tudo o que vimos e passamos, e depois prosseguir. 
$\mathrm{Na}$ aventura de cada família, ela vem ao nosso encontro, às vezes apenas de passagem. Seria muito bom para ela, que tal como naquela estalagem à beira do caminho, encontrasse alguém esperando por ela, para poder servi-la, aliviá-la de suas demandas e restabelecer-se, recuperando forças para prosseguir o caminho.

Nosso mundo na enfermagem, sem uma concepção do humano seria muito pequeno. Nossa chance de ampliá-lo nos é dada pelas famílias que chegam até nós e que nos permitem viver com elas um pouco de sua aventura. Assim, algum dia poderemos nos lembrar destes encontros e contar histórias de um lugar em que uma família pode descansar, outra que tomou importantes decisões em sua vida ou ainda a que reuniu suprimentos para prosseguir a sua jornada. Um lugar em que alguém estava com a família em tempos difíceis.

Às vezes é difícil para um enfermeiro ser humano. Parece um absurdo fazer tal observação, mas o fato é que há momentos em que ele se sente como se estivesse andando na contramão ou tentando caminhar fora do sulco provocado pelas rodas num caminho de terra. É preciso muita atenção a este tipo de caminho já traçado. Quando caminhamos por alí parece confortável, no entanto, com o passar do tempo e das rodas, 0 sulco vai se aprofundando e chega a destruir o terreno ao redor, impedindo a possibilidade de um novo traçado. Assim, é importante arriscar novos caminhos, até para garantir a sobrevivência do terreno.

É necessário mover-se de uma espontaneidade irreflexiva, um simples deixar-se levar pela correnteza, para ações orientadas pela nossa vontade. A educação da vontade pressupõe uma consciência de si mesmo e quando retamente exercida, é um requisito para viver em dimensão de liberdade. Ser livre é poder decidir, até de quem "eu" preciso cuidar, não se limitando a viver de automatismos.

Assim, estar com a família em tempos difíceis para ela, é um apelo ao humanismo possível em cada enfermeiro. Insis to nesta idéia, por acreditar que somente a presença do humano nas angústias e perplexidades que $o$ ato de intervir no processo saúde-doença acarreta, torna possível fazer emergir coerência onde parecia reinar o caos e transformar em momento de crescimento os conflitos do dinamismo do sofrimento da família face a crise experienciada pela doença. Isto é cuidar da família. Isto é enfermagem da família. Este é sem dúvida um imenso desafio.

ABSTRACT: Family perspective is influencing nursing practice and theory. Despite this development, there are enough evidences on research and on students and nurses narratives about the difficulties for being with families in nursing situations. In this article, the author analyses three challenges that can help nurses getting close to families: teaching to think family, stimulating an advanced practice with families and constructing the knowledge on family nursing. The author concludes that overcoming the callings will increase the caring possibilities for nurses and families.

KEY WORDS: Family; Nursing.

\section{REFERÊNCIAS BIBLIOGRÁFICAS}

1. ANGELO, M.; PETTENGILL,M.M. Ensino sobre família nos cursos de graduação em enfermagem no Brasil. . Projeto de pesquisa. Escola de Enfermagem da Universidade de São Paulo, 1997. 11p (Mimeografado).

2. CHESTERTON, G. K. El amor o la fuerza del sino. 3. ed. Madrid : RIALP, 1995.

3. DAVIES, B. Windows on the family. The Canadian Nurse, p.37-41, 1995.

4. DUHAMEL, F. The practice of family nursing care: still a challenge! Canadian J ournal of Nursing Research, v.27, n.1, p.7-11, 1995.

5. FRIEDMAN,N. Teaching about and for family diversity in nursing. J ournal of Family Nursing, v.3, n.3, p.280-94, 1997.

6. GREEN,C.P. Teaching students how to "think family". J ournal of Family Nursing, v.3, n.3, p.230-46, 1997.

7. HANSON,S.M.H.;HEIMS,M.L. Family nursing curricula in U.S.Schools of Nursing. J ournal of Nursing Education, v.31, n.7, p.303-8, 1992.

8. MARTINO, A. D. The family institution bound for the XXI century. Italy, 1995. 36p (mimeografado)

9. NEMAN, F. A. Fazendo algo a mais: a percepção do aluno de enfermagem sobre o cuidado realizado no contexto da família. 1996. Dissertação (Mestrado) - Escola de Enfermagem, Universidade de São Paulo.

10. TAPP,D. M.; MOULES, N.J .; BELL, J. M.; WRIGHT, L. M. Family skills labs: facilitating the development of family nursing skills in the undergraduate curriculum. J ournal of Family Nursing, v.3, n.3, p.247-66, 1997.

11. WRIGHT,L.M.;BELL,J.M. A survey of family nursing education in canadian universities. The Canadian J ournal of Nursing Research, v.21, n.3, p.59-74, 1989. 